\title{
As noções de gestos e de agir didático para a formação de professores de línguas: interfaces do trabalho docente
}

Carla Messias* Joaquim Dolz**

\author{
*Universidade de Genebra \\ (Genebra, Suíça) \\ **Universidade de Genebra \\ (Genebra, Suíça)
}

Resumo: Neste artigo, discutiremos as noções de gestos fundamentais e de agir didático de professores de língua portuguesa do ensino fundamental. A identificação dos gestos e do agir didático nas atuações dos professores podem servir para uma melhor compreensão do trabalho docente. A focalização que fazemos neste artigo se dá em relação às intervenções do professor em sala de aula, especificamente no que tange ao desenvolvimento de um objeto de ensino relativamente às aprendizagens dos alunos. Para discutir esses dois conceitos, pautamo-nos nos campos teóricos relacionados às ciências do trabalho, à Linguística Aplicada e à Didática das Línguas. Metodologicamente, discutimos os procedimentos realizados em duas pesquisas sobre três objetos de ensino diferentes: subordinada relativa, texto argumentativo e a leitura de textos narrativos. A identificação dos gestos e do agir didático na atuação dos professores sobre esses objetos visa a aprendizagens específicas gramaticais, discursivas e leitoras dos alunos. Nossos resultados mostram que as noções de agir e de gesto didático podem contribuir para uma maior compreensão do trabalho do docente. Elas podem também ser usadas pelos professores a fim de melhorar suas formas de atuação em sala de aula.

Palavras-chave: Agir didático. Ensino-aprendizagem. Gestos didáticos. Trabalho docente. 


\section{INTRODUÇÃO}

Discutir as noções de gestos e de agir didático dos professores não é uma tarefa fácil. Elas podem ser compreendidas e interpretadas muitas vezes como noções redutoras do complexo trabalho docente. Entretanto, partimos de uma perspectiva sociointeracionista em que para compreender o todo do sistema precisamos nos ater às partes que o constituem, observando-as dialogicamente.

Entre os anos 1930 e 1950 e início dos anos 1960, as pesquisas referentes ao trabalho do professor e os critérios de "eficácia" de suas ações recebiam forte influência da abordagem positivista. 0 objetivo era formar professores de acordo com a "imagem ideal do bom professor" (AMIGUES, 2003, p. 5). Já nos anos 1970, as pesquisas visavam sobretudo definir a eficácia do professor medindo os resultados do ensino relativamente à aprendizagem dos alunos. Em outras palavras, tratava-se de estabelecer relações entre o processo de ensino e as performances dos alunos. Segundo Amigues (2003), a perspectiva adotada considera que as aprendizagens dos alunos dependem diretamente das ações do professor, sendo algumas mais eficazes do que outras. O professor é o detentor do saber e suas ações são as únicas responsáveis pelos resultados obtidos no processo de ensino-aprendizagem. Desse modo, os alunos seriam recipientes a serem preenchidos pelas ações dos professores. A relação estabelecida nesse paradigma é a de causa e efeito, estímulo e resposta.

Em um período posterior, o paradigma behaviorista, em contexto educacional, é substituído pela corrente cognitivista. Essa mudança de paradigma influencia a concepção do trabalho docente. A ação do professor passa a ser vista sob dimensões de planejamento, de tomada de decisões e de avaliação do processo educativo. Cabe ao professor criar o ambiente favorável para a aprendizagem de seus alunos, planejando-o e adaptando-o às situações que surgem. $\mathrm{O}$ que se percebe como resultado desse paradigma é a centralidade na ação do professor, sendo ele o único responsável pelos problemas de aprendizagem em contexto educacional. Embora acreditemos que essa seja uma tarefa do professor, ela não deve ser dissociada dos contextos mais amplos que influenciam todo o processo de ensino-aprendizagem.

Por mais que discutamos a existência desses dois paradigmas em ordem cronológica, ressaltamos que ao debater a temática sobre o trabalho do professor, atualmente, essas visões se interlaçam. Entretanto, podemos afirmar que a partir do século XXI, uma concepção sociointeracionista se 
torna mais presente e traz a visão da complexidade do trabalho docente. Esse trabalho passa a ser compreendido, de acordo com Machado (2010, p. 165), pautando-se em estudos da Clínica da Atividade e da Ergonomia da Atividade, como "uma atividade situada influenciada pelas condições sócio-históricas de uma determinada sociedade" e orientada por prescrições tanto do sistema educacional quanto do sistema de ensino, que acabam por apresentar "modelos de agir”. É impessoalizada, pois as prescrições são dirigidas a todos os docentes de modo geral, independentemente da situação específica, e ao mesmo tempo é pessoal, porque é “própria de cada professor, que, para realizá-la, mobiliza seu ser integral, em múltiplas dimensões (físicas, cognitivas, linguageiras, afetivas etc.)". É considerada ainda como finalizada por ter como objetivo "a construção de um ambiente propício à aprendizagem de determinados conteúdos pelos alunos e ao desenvolvimento de determinadas capacidades a eles relacionadas". E instrumentada, pois o professor apropria-se de artefatos que se tornam ferramentas propícias para as tarefas que realiza. Vale ressaltar que em se tratando do trabalho docente, esses instrumentos são ferramentas semióticas, no sentido vigotskiano do termo, que contribuem para transformar as aprendizagens dos alunos e as práticas profissionais dos professores (WIRTHNER, 2006; SCHNEUWLY; DOLZ, 2009). E, por fim, é considerada como interpessoal porque se desenvolve no diálogo e nas interações entre vários sujeitos (entre os professores, entre o professor e os alunos e entre os próprios alunos nas tarefas coletivas impulsionadas pelo professor).

As pesquisas mais recentes no campo da Linguística Aplicada (doravante LA) de universidades brasileiras ${ }^{1}$ e da Didática de Línguas da Universidade de Genebra² tomam o trabalho do professor como objeto privilegiado,

Grupos “Análise de Linguagem, Trabalho Educacional e suas Relações (Alter/Lael - 20032012)", criado em 2003, sob a liderança de Anna Rachel Machado (PUC/SP); "Análise de Linguagem, Trabalho Educacional e suas Relações/Gêneros Textuais (Alter/GET)”, criado em 2008, sob a liderança de Vera Cristóvão (UEL) e Antónia Coutinho (UNL-PT); “Análise de Linguagem, Trabalho e suas Relações: Aprendizagens, Gêneros Textuais e Ensino (Alter/AGE)", criado em 2011, sob a liderança de Eliane Lousada (USP/SP); "Livros, materiais didáticos e trabalho docente: um percurso pela História e as contribuições para o ensino e a formação", criado em 2015 sob a liderança de Lilia Abreu-Tardelli (Unesp/SP); "Ensino e aprendizagem na perspectiva da Linguística Aplicada: análise do discurso do professor em formação sobre o seu trabalho no estágio", criado em 2014 sob a liderança de Eulália Leurquin (UFC); e "Análise de Linguagem, Trabalho e suas Relações -Letramento, Gêneros Textuais e Ensino (Alter-Lege)”, criado em 2015, sob a liderança de Luzia Bueno (USF), entre outros.

Groupe de Recherche pour l'Analyse du Français Enseigné (Grafe), sob a liderança de Bernard Schneuwly e Joaquim Dolz (Unige); e "Formation des enseignants en didactique du français (Grafe-Forendif)”, criado em 2009 sob a liderança de Joaquim Dolz (Unige). 
abordando-o, de uma parte, sob a influência do contexto sócio-históricopolítico e das condições do trabalho institucional, e por outra parte, sob os aspectos do trabalho efetivamente realizado: ora dando ênfase às situações de trabalho e suas especificidades (interação professor-aluno; relação professorinstituição; o professor e as prescrições, etc.), ora dando ênfase às ferramentas profissionais que permitem o desenvolvimento desse trabalho (elaboração de material didático; análise dos objetos de ensino; intervenções dos professores em contexto de sala de aula, etc.) e ora enfatizando a análise das funções da linguagem no trabalho. As primeiras pesquisas brasileiras integraram, em sua maioria, o nível da transposição didática externa (transformação do objeto do saber ao objeto a ser ensinado que ocorre anteriormente à entrada do professor em sala de aula) e as pesquisas genebrinas focalizaram no nível da transposição didática interna (a dinâmica de construção do objeto ensinado que ocorre concretamente na situação de sala de aula). Nos dois casos, o papel da linguagem é considerado fundamental para a análise do trabalho do professor.

No quadro deste artigo propomos discutir a complementariedade entre as duas perspectivas mencionadas para o estudo do agir didático do professor e dos gestos que o caracterizam. Ressaltamos a importância de observar empiricamente o agir didático nas práticas da aula e de operacionalizar os gestos didáticos em função das intervenções efetivas dos professores para os diferentes objetos de ensino, ou seja, centrados na transposição didática interna. Neste artigo, vamos sintetizar os resultados das pesquisas mencionadas para responder de forma mais específica a três questões gerais:

- Como se caracteriza o agir didático do professor de línguas e quais são os gestos profissionais que ele mobiliza no seu trabalho?

- Quais são os critérios para observar o agir didático do professor e para diferenciar os gestos que caracterizam sua ação?

- Em que medida essas noções podem servirà formação dos professores? Como a apropriação desses conceitos pelos professores contribui para o processo ensino-aprendizagem de diferentes objetos de ensino?

Para responder a nossas questões, organizamos nossa proposição em três seções. Na primeira, discutimos o trabalho e o papel do professor de línguas. Na segunda parte, debateremos sobre a importância das noções de agir didático e gestos fundamentais, suas origens e influência no processo de compreensão do trabalho docente. Na terceira parte, central da nossa contribuição, exemplificaremos as pesquisas realizadas pelos autores deste artigo, precisando o procedimento metodológico e os principais resultados. 
Enfim, na última parte, apresentamos as potencialidades desses conceitos para o processo de formação do professor e para o desenvolvimento do trabalho docente.

\section{O TRABALHO DO PROFESSOR DE LÍNGUAS}

O trabalho do professor, de modo geral, é constituído por diferentes tarefas que exigem diferentes intervenções. Em sala de aula, essas intervenções podem ser consideradas como intervenções didáticas quando se referem especificamente às ações realizadas para o desenvolvimento da aprendizagem dos alunos. Fora da sala, mas também voltadas para as funções que fazem parte do trabalho docente, podemos identificar intervenções como preencher relatórios, participar de reuniões pedagógicas e com os pais dos alunos, participar de formação continuada, etc., conforme buscamos mostrar na Figura 1, a seguir.

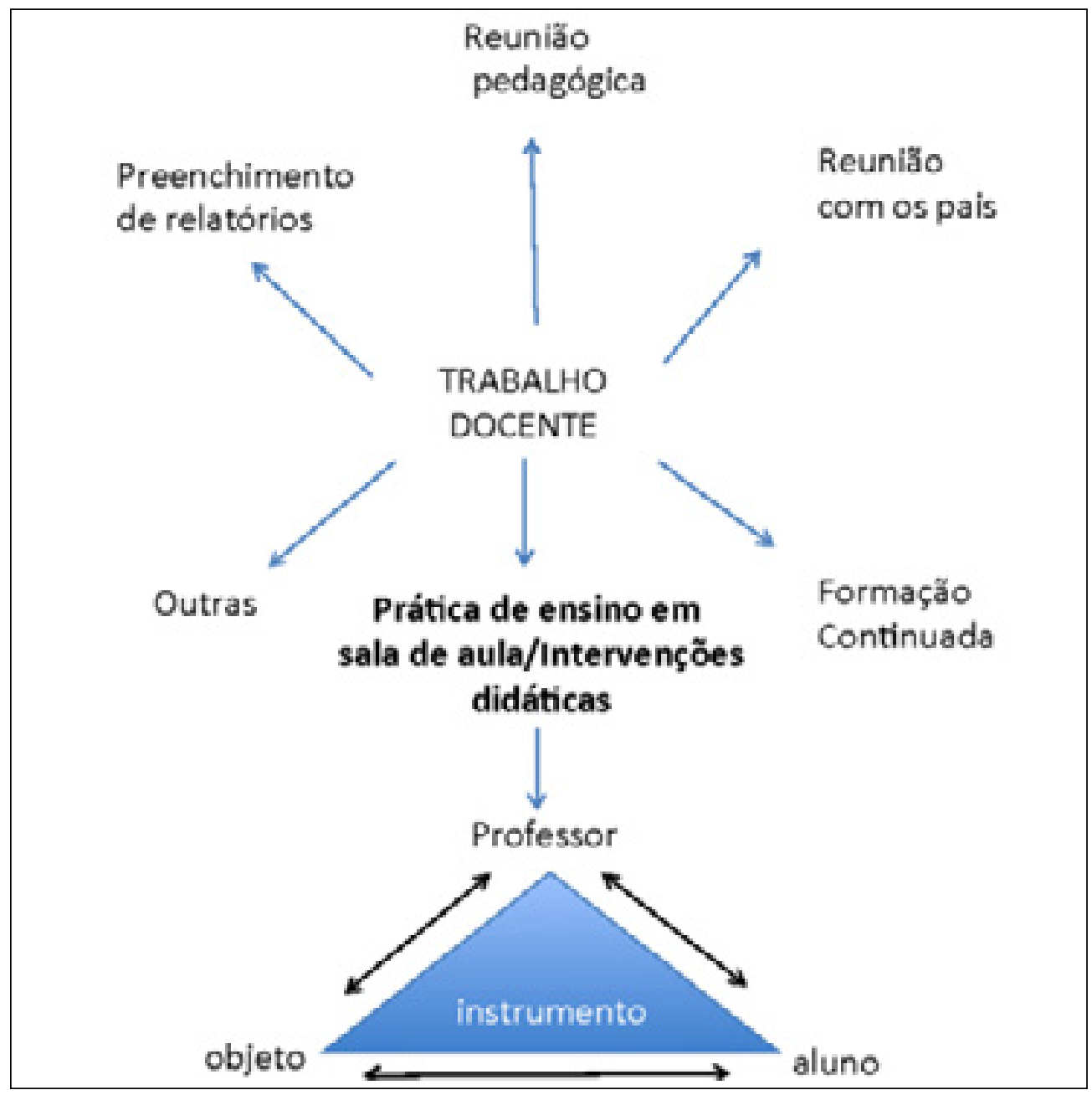

Figura 1 - Diferentes facetas do trabalho do professor

Fonte: Silva (2013, p. 130). 
Na Figura 1, destacamos, em negrito, a função central do docente, que é voltada para as práticas de ensino e a aprendizagem de um objeto de ensino por meio das intervenções didáticas, a fim de possibilitar o desenvolvimento de diferentes capacidades nos aprendizes. Em outras palavras, essa função refere-se à situação em que professores e alunos em interação transformam o objeto de ensino em objeto ensinado e apreendido. 0 ato de ensinar de um professor de línguas exige o domínio da língua ensinada (português, inglês, espanhol, etc.), mas também o domínio da disciplina escolar (matéria Língua Portuguesa no currículo escolar brasileiro, Inglês Língua Estrangeira, etc.). Para poder ensinar, o professor tem de transpor os seus conhecimentos, as suas experiências de ensino e as suas habilidades profissionais para conseguir uma aprendizagem. Tem de saber avaliar as capacidades linguageiras dos alunos e a sua progressão. Tem de saber mobilizar os suportes e os materiais para o ensino (livros, documentos, multimídias, etc.). Finalmente, tem de saber gerenciar o grupo heterogêneo de alunos, garantindo um contexto favorável para a aprendizagem da língua portuguesa ou das outras línguas ensinadas na escola para todos. Esse conjunto de elementos caracteriza o agir didático.

Consideramos que essa tarefa é central ao trabalho docente independentemente da disciplina ministrada por um professor. No caso de nosso artigo, incidiremos, de modo mais específico, ao trabalho do professor de língua portuguesa e suas especificidades.

0 primeiro elemento que diferencia o trabalho do professor de língua portuguesa (língua primeira) do trabalho de outras disciplinas é o objeto geral de ensino. Esse objeto é a própria língua em seus diferentes aspectos ou dimensões. Isso envolve, de um lado, conteúdos ligados às habilidades e às capacidades práticas: falar, ouvir, escrever, ler, interagir com o outro, compreender; e, de outro lado, implica questões relativas aos saberes e às normas. Do professor de língua espera-se que ele conheça a língua e seus componentes, como, por exemplo, a gramática, o léxico, a ortografia, o vocabulário, bem como a comunicação oral e escrita, a literatura e aspectos culturais inerentes à dimensão dos textos. É, portanto, um trabalho que tem a mesma estrutura de todo trabalho docente, entretanto, ele age sobre a linguagem.

Nesse caso, ele recebe influências de campos teóricos que estudam a língua e a linguagem. Atualmente, em contexto brasileiro, reconhecemos duas correntes de estudiosos da língua e da linguagem que podem influenciar o trabalho dos professores de LP. De um lado, temos pesquisadores e estudiosos 
que discutem e são por uma concepção de Língua Brasileira (ORLANDI, 2002), pautando-se em diferenças linguísticas, culturais e políticas. E, de outro lado, temos pesquisadores que discutem a LP no Brasil como uma variedade do português, podendo ser considerado Português-Brasileiro (CASTILHO, 2010), argumentando sobretudo que as diferenças não sejam suficientes para constituir-se uma nova língua, mas uma variedade com regras gramaticais próprias.

Neste artigo, optamos por utilizar LP referindo-se à variante brasileira, como consta nas prescrições nacionais, mas reconhecemos que as concepções teóricas que vêm sendo discutidas desde o final do século XIX (entre tradicionalistas e nacionalistas) e a partir do século XX (entre tradicionalistas e não tradicionalistas) influenciam o trabalho do professor de línguas que as tem como objeto de ensino. Ser professor de língua, nesse contexto, não é tarefa fácil, pois seu objeto de ensino está em constante questionamento, movimento e/ou desenvolvimento. A língua não é estática, ela se transforma e se recria. 0 que e como ensinar então? Para responder a essa questão, os currículos escolares elaborados por pesquisadores e estudiosos da língua integram as prescrições nacionais, a fim de solucionar de modo geral essa problemática.

No que concerne a essa questão, reconhecemos, assim como Dolz, Gagnon e Decândio (2009), que o currículo ou o programa para o ensino de línguas é amplo, comportando sempre escolhas relacionadas aos diferentes campos teóricos como, por exemplo, linguística, literatura, sociolinguística, linguística textual, filosofia da linguagem, pragmática, etc., o que torna esse trabalho complexo. Ensinar, nesse contexto, consiste em transformar ou possibilitar diferentes formas de pensar, de falar, de fazer, de interpretar, com a ajuda de ferramentas/instrumentos semióticos: os signos ou os sistemas linguísticos ou linguageiros, os textos. Mas é importante ressaltar ainda que esse trabalho compreende diferentes facetas, podendo ser considerado como um trabalho metalinguageiro por representar, sobretudo, um agir com a língua e sobre a língua. Nesse caso, reconhecemos a língua como objeto de ensino e como ferramenta semiótica para o ensino.

Destacamos que no processo de ensino-aprendizagem, visando ao desenvolvimento das capacidades dos alunos, professores realizam diferentes intervenções didáticas que podem ser consideradas como gestos didáticos e que constituem o seu agir na realização da tarefa central de seu métier, conforme discutiremos a seguir. 


\section{AS NOÇÕES DE GESTOS E DE AGIR DIDÁTICO}

Nesta seção, discutiremos a noção de gestos didáticos fundamentais tal como discutida pela equipe de pesquisadores do grupo Grafe da Universidade de Genebra (SCHNEUWLY; DOLZ, 2009) e a noção de agir didático tal como discutida na tese de Silva (2013) ${ }^{3}$.

\subsection{Os gestos didáticos fundamentais}

Em relação aos gestos didáticos, destacamos que eles têm sua origem na discussão existente sobre os gestos profissionais. A noção de gestos profissionais se encontra no cruzamento de campos teóricos e práticas sociais nem sempre convergentes: a didática, a teoria da ação, a ergonomia, clínica da atividade, ciências da educação. Estando nesse cruzamento de campos, eles podem ser compreendidos, de forma geral, como gestos linguageiros e não linguageiros, realizados por um trabalhador na realização de seu métier (BUCHETON; DEZUTTER, 2008); ou como formas características da intervenção de um trabalhador em seu trabalho, conforme considerações de Dolz em entrevista concedida a Silva e Silva (2012), ou ainda como o conjunto do que é identificável, objetivado e possível de ser transmitido por trabalhadores no desenvolvimento de seu métier (BUCHETON, 2008).

Em contexto escolar, mais especificamente no que se refere ao métier docente, teremos os gestos profissionais dos professores, que, segundo Bucheton (2008), são realizados em contextos que são a cada vez únicos, pois os atores e seu engajamento, sua identidade, seus conhecimentos, suas experiências, a natureza do contexto didático, a cultura da classe, o tempo, os efeitos, os eventos e retroações que os gestos geram ou não são sempre diferentes. Além de ser únicos, a finalidade dos gestos profissionais dos professores é contribuir para criar o espaço da palavra e do trabalho para que os currículos sejam transmitidos e apropriados pelos alunos (BUCHETON, 2008).

Os gestos profissionais dos professores são, sobretudo, gestos linguageiros aos quais se acoplam gestos não linguageiros. A concepção do papel da linguagem no desenvolvimento da pessoa, nas interações entre elas, é a base dessa concepção de gestos. De acordo com Bucheton (2008, p. 39), a escolha da palavra "gestos" está relacionada às possibilidades semânticas e metafóricas que esse termo oferece, podendo referir-se à palavra ou aos movimentos corporais.

Tese intitulada "O agir didático do professor de Língua Portuguesa e sua reconfiguração em textos de autoconfrotação", defendida em dezembro de 2013 por Carla Messias, co-autora do presente artigo. 
Na concepção da didática, os gestos dos professores são didáticos desde que eles visem aos saberes, aos modos de pensamento e de agir que em seu conjunto contribuem para o desenvolvimento global do aprendiz no processo de ensino-aprendizagem. Para Dolz, em entrevista concedida a Silva e Silva (2012, p. 19), o termo gesto profissional do professor é geral e "permite caracterizar as funções e as tarefas do professor independente da matéria de ensino", e os gestos didáticos são característicos do professor de uma matéria específica. Portanto, os gestos didáticos são os gestos do professor quando consideramos a matéria de ensino e o conteúdo a ser ensinado - o objeto de ensino.

Os gestos didáticos, tais como postulados pela equipe de pesquisadores da Didática das Línguas do grupo Grafe, inspiram-se na noção de "gestus" criado pelo dramaturgo Brecht, que diz respeito não apenas à simples gestualidade não verbal, mas também à possibilidade de criar atitudes genéricas/gerais que os gestos podem realizar, abarcando o tom de voz, toda a gestualidade, as atitudes, a vestimenta, enfim, toda a caracterização da personagem pelo autor.

Ao transpor esse conceito para suas pesquisas em Didática das Línguas, numa preocupação quanto ao trabalho do docente de língua francesa (primeira língua) em sua relação com os objetos de ensino, os pesquisadores do grupo Grafe vão postular a existência, na atividade de ensino, de gestos fundamentais que se integram ao sistema social complexo da atividade docente e que são regidos por regras e códigos convencionais, estabilizados pelas práticas, já secularizadas, da cultura escolar. Esses gestos são compreendidos de forma mais ampla como gestos linguageiros associados também a gestos não linguageiros. (SCHNEUWLY, 2009).

Ao trabalhar com a noção de gestos fundamentais, eles estabelecem, de modo geral, que esses gestos na profissão do professor supõem uma clarificação das situações de ensino, dos dispositivos e das atividades escolares, bem como das ferramentas em uso que permitem a ação do professor, limitandoas e estudando-as sob o ponto de vista didático, numa preocupação que recai sobre o plano da transposição didática interna, ou seja, das mudanças que um objeto de ensino sofre no processo de interação entre professores e alunos no desenvolvimento de uma aula. Dessa maneira, a concepção de gestos didáticos fundamentais, tal como discutida pelo grupo Grafe, leva em consideração as intervenções dos professores em relação ao objeto de ensino, a fim de que ele se torne objeto ensinado, apreendido e apropriado pelos alunos. 
Aeby-Daghé e Dolz (2008), ao apresentarem os gestos didáticos fundamentais e específicos, referindo-se aos primeiros como "fundadores" e retomando Schneuwly (2000), postulam a existência de sete gestos didáticos fundadores os quais podem, de acordo com as intervenções dos professores, gerar diferentes gestos específicos. Quanto aos gestos didáticos fundadores, eles os identificam como gestos de presentificação, de focalização ou elementarização, de formulação das tarefas, de implementação do dispositivo didático, de criação de memória didática, de regulação e de institucionalização.

Em relação a esses gestos, Schneuwly (2009), retomando o trabalho de AebyDaghé e Dolz (2008), discute a existência de quatro gestos fundamentais: 0 de implementação do dispositivo didático, o de criação da memória didática, o de regulação e o de institucionalização, aos quais se ligam os gestos de presentificação e elementarização ou focalização. Para Schneuwly (2009), esses dois últimos integram o gesto de implementação do dispositivo didático.

Os quatro gestos didáticos podem ser compreendidos como:

- implementação do dispositivo didático: forma ou intervenções didáticas que apresentam o objeto de ensino, tornando-o presente aos alunos pelo subgesto de "presentificação" e delimitando as suas dimensões a serem estudadas pelo subgesto de "focalização". Tomemos como exemplo desse gesto a implementação de um dispositivo didático elaborado por um professor para a realização de uma aula de leitura, visando ao desenvolvimento de capacidades leitoras e interpretativas de contos em alunos do sexto ano do ensino fundamental. $\mathrm{Na}$ implementação de um dispositivo didático sobre "leitura dirigida”, por exemplo, em que o professor leva para a sala diferentes contos, deixando os alunos escolherem os contos a ser lidos e, em seguida, propõe a cada um deles que os leiam, identificando os personagens, a interação entre eles e o conflito central do enredo, o professor realiza ações. Essas ações verbais orais e/ou escritas (por exemplo, as consignas ou instruções sobre o que fazer) e não verbais (por exemplo, as expressões corporais, o ato de entregar os livros, deixando-os sobre a mesa para os alunos irem escolher) realizadas pelo professor constituem o gesto de implementação do dispositivo. Ao levar os contos e deixar os alunos escolherem os de sua preferência, o professor presentifica o objeto de ensino. Ao indicar os parâmetros a ser observados, o professor focaliza os elementos a ser estudados.

- regulação: formas de realização de intervenções dos professores na superação dos obstáculos de aprendizagens dos alunos. Ainda tomemos como exemplo o dispositivo "ciclo de leitura". No momento 
de sua implementação, pode haver obstáculos quanto à leitura e à interpretação dos alunos quando questionados sobre a relação entre as personagens ou o conflito central do enredo. As diferentes maneiras realizadas pelos professores, a fim de mediar ou sanar as dúvidas e os obstáculos, como por exemplo, reelaboração das consignas, exemplificação de outros contos ou situações, constituem o gesto de regulação. Ressaltamos que no ato de regular, o professor não deve dar uma resposta imediata aos alunos, mas sim criar meios para que seus aprendizes encontrem as respostas e superem seus obstáculos, dando-lhes autonomia para encontrar as respostas.

- criação de memória didática: intervenções que designam a construção de um conhecimento comum a ser partilhado pela sala, colocando em relação o que foi ensinado anteriormente com o que está sendo ensinado, por meio de retomadas de conteúdos. Por exemplo, momentos em que um professor retoma conteúdos estudados anteriormente. Este gesto pode ser marcado por retomadas linguísticas como "Em nossa aula anterior estudamos o conto 'O Menino Maluquinho', de Ziraldo, vocês se lembram? Hoje estudaremos outro conto". Esse gesto é extremamente importante para a manutenção do elo entre os conteúdos estudados. Ainda quanto a esse gesto, Silva (2013) apresenta dois movimentos de criação de memória didática: o movimento externo e o movimento interno a uma sequência de ensino. O primeiro "refere-se às retomadas de conteúdos discutidos em outras sequências, a fim de criar ou estabelecer relação entre os conteúdos" (SILVA, 2013, p. 224), por exemplo, quando um professor retoma características de um gênero textual (o artigo de opinião) trabalhado em uma sequência de outro gênero textual (dissertação escolar). Já o movimento interno "refere-se às retomadas do conteúdo discutido inicialmente no interior da mesma sequência de ensino" (SILVA, 2013, p. 224). Como em um momento em que um professor, ao estudar a elaboração de argumentos para a produção escrita de um artigo de opinião, retoma exemplos de argumentos já produzidos por alunos ou algum expert em textos que integrem a mesma sequência de ensino.

- institucionalização: processo pelo qual os professores agem a fim de fixar os conhecimentos já instituídos social e coletivamente por especialistas, a respeito de um objeto de ensino. Por exemplo, quando um professor de nono ano do ensino fundamental, no estudo sobre o "personagem tipo" de contos ou romances, discute com seus aprendizes as características dos personagens, fixando as ideias sobre aqueles considerados heróis e anti-heróis ou protagonistas e 
antagonistas, ele está realizando o gesto de institucionalização. Esse ato de institucionalizar pode ser realizado por meio de ações verbais orais ou escritas.

Esses gestos, embora discutidos no campo do ensino de línguas (didática do francês), podem ser observados em qualquer situação de ensino, independentemente do objeto a ser ensinado, bem como outros contextos de investigação podem mostrar outros gestos que podem constituir as ações dos professores no processo de transposição didática interna. Como exemplo, podemos destacar a pesquisa de Silva (2013) que, baseada nessas quatro noções de gestos fundamentais, identificou o gesto de planejamento e os gestos didáticos específicos ligados a cada gesto fundamental.

Quanto ao gesto de planejamento, ele é considerado como um "gesto didático fundamental que antecede os outros gestos didáticos" e "que exerce influência sobre eles", "é o primeiro momento em que um objeto de ensino passa pela primeira "transformação” (SILVA, 2013, p. 300). Para a autora, "o professor, ao planejar, faz a primeira focalização das dimensões a serem privilegiadas do objeto na prática didática que pretende realizar”. 0 ato de planejar é considerado como gesto, pois envolve a transposição didática dos conceitos teóricos e as propostas curriculares para o contexto de sala de aula, levando em consideração o nível escolar dos alunos. Ao discutir essa noção de gesto de planejamento, a autora não descarta a possibilidade dos limites que esse planejamento pode ter, isto é, “os imprevistos que podem ocorrer nas situações imediatas ou práticas efetivas, durante a formação em sala de aula e que, consequentemente, podem transformar o planejamento realizado" (SILVA, 2013, p. 300).

Esse gesto é muito importante para a planificação do ensino e implica a preparação dos materiais a ser utilizados pelos professores e alunos no decorrer de uma aula, bem como a elaboração dos dispositivos didáticos e a antecipação dos possíveis obstáculos a ser enfrentados pelos aprendizes quanto ao objeto de ensino. É importante destacar que como esse gesto antecede a aula, o professor precisa ter tempo e condições favoráveis para preparar e/ou elaborar o que irá fazer, os métodos a ser realizados, a fim de alcançar aos objetivos de desenvolvimento das capacidades dos aprendizes.

Neste artigo que reúne o resultado de nossas pesquisas, discutiremos, na seção 3, a importância das noções dos cinco gestos didáticos considerados por nós como fundamentais (planejamento, implementação do dispositivo didático, regulação, criação de memória didática externa e interna e institucionalização) para o contexto de formação de professores. 


\subsection{0 agir didático}

A noção de agir didático tem sua origem na concepção de agir como "qualquer forma de intervenção orientada de um ou de vários seres humanos no mundo" (BRONCKART, 2008, p. 120). Compreendendo o agir como condutas conscientes e intencionais do humano sobre uma situação ou um objeto, Silva (2013) postula que o agir didático é uma dimensão do agir docente (MACHADO et al., 2009), voltado, especificamente, para as intervenções de caráter didático. Desse modo, tomando como princípio o termo agir como forma de intervenção orientada, Silva (2013) apresenta o agir didático como as intervenções dos professores no momento da transposição didática interna, isto é, nos momentos em que as ações dos professores visam estritamente ao ensino e à aprendizagem dos alunos sobre determinado objeto de ensino, visando ao desenvolvimento de diferentes capacidades. Além disso, esse agir é considerado pela autora como uma dimensão do agir docente.

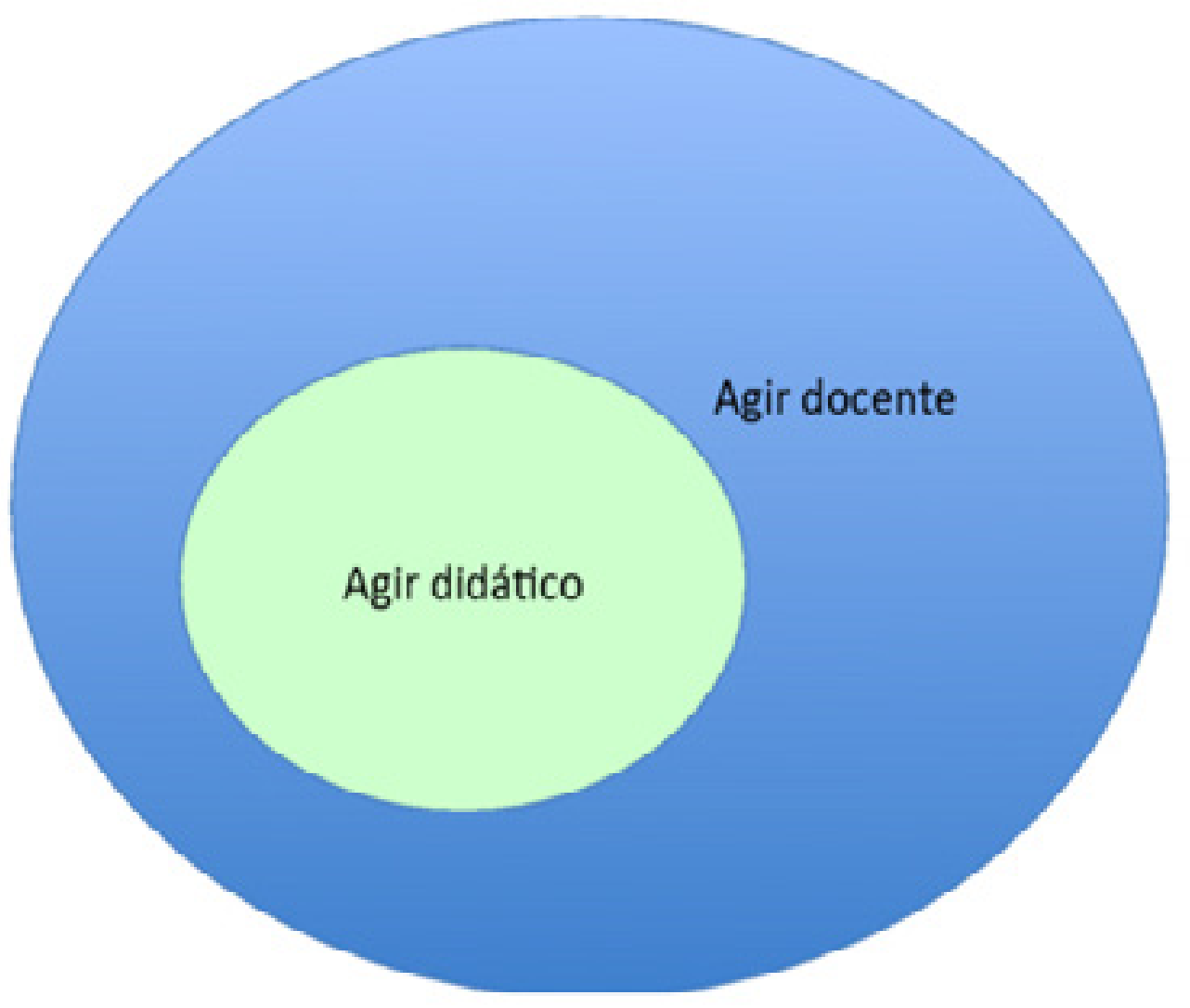

Figura 2 - 0 agir didático como uma dimensão do agir docente Fonte: Silva (2013).

A Figura 2 busca representar o agir didático como uma dimensão do agir 
docente. No que se refere ao agir docente, ele pode ser considerado e observado nas formas de intervenções realizadas pelos professores em diferentes situações de trabalho, sejam relacionadas à situação de sala de aula durante o processo de ensino-aprendizagem de um objeto de ensino, sejam relacionadas às outras situações que correspondem também ao trabalho complexo do professor (MACHADO, 2010). No que tange ao agir didático, ele é a dimensão do agir docente que se refere especificamente ao processo de ensino-aprendizagem, conforme já referido. Ao observarmos um professor, isto é, o que ele faz profissionalmente, como, por exemplo, o gesto de planejar e elaborar os dispositivos didáticos, momento que antecede a aula propriamente dita, constatamos que faz parte do agir didático.

De acordo com Silva (2013), o agir didático pode ser geral ou específico:

\begin{abstract}
[...] geral quando se refere às intervenções que podem ser realizadas independentemente do conteúdo escolar ou objeto de ensino desenvolvido em uma aula como, por exemplo, as intervenções que visem o desenvolvimento de estratégias e de formas sociais de trabalho como o debate ou o trabalho em grupo que pode ser realizado em qualquer disciplina sobre qualquer conteúdo; e específico quando se refere às intervenções realizadas na situação de interação particular voltada para o objeto de ensino escolhido para uma prática como, por exemplo, as intervenções em que um professor adapta o conteúdo escolar ao nível dos alunos em uma disciplina específica (SILVA, 2013, p. 370).
\end{abstract}

Observamos que tanto numa perspectiva geral quanto numa perspectiva específica, esse agir se refere às intervenções que um professor faz em interação com seus alunos no momento de ensino e aprendizagem de um objeto de ensino ou às intervenções de planejamento e construção de um dispositivo de ensino. Essas intervenções, no quadro de nossas pesquisas, são os gestos didáticos fundamentais e seus subgestos ou gestos específicos que podem constituí-los. Esse agir é, portanto, observado no processo de transposição didática interna.

Entretanto, sua temporalidade não se restringirá apenas ao momento de realização de uma prática em sala de aula, mas é também constituído por intervenções precedentes ou posteriores a ela desde que tenham funções estritamente didáticas.

Em outras palavras, as intervenções que antecipam a prática dizem respeito ao gesto de planejamento. 0 ato de planejar, portanto, faz parte do agir didático.

As intervenções durante a prática de ensino são concernentes aos gestos de implementação do dispositivo, regulação, criação de memória didática e 
institucionalização, e também integram o agir didático. Por exemplo, quando um professor presentifica o objeto de ensino e focaliza suas dimensões por meio das consignas/instruções dadas aos aprendizes ou quando ele busca maneiras de superar os obstáculos dos alunos quanto às dificuldades de compreensão de um conto ou ainda recorre à memória didática para introduzir ou explicar um conteúdo, está agindo didaticamente, isto é, essas ações são agir didático.

E as intervenções posteriores podem ser de avaliação de uma sequência de ensino, sua eficácia e sua coerência, tendo em relação o conteúdo escolar estudado e o nível escolar dos alunos, a avaliação do próprio professor sobre suas intervenções realizadas e a avaliação dos alunos quanto às suas aprendizagens adquiridas.

Vale a pena destacar que, embora a noção de agir didático tenha sido discutida inicialmente no desenvolvimento de uma pesquisa que buscou primeiro observar as intervenções de professores no processo de ensinoaprendizagem da leitura de dois gêneros textuais, essa noção pode ser estendida às intervenções voltadas a outros objetos de ensino. Acreditamos ainda que, se ampliarmos as pesquisas a outros objetos e situações de ensino, a noção inicialmente elaborada pode enriquecer-se.

De um modo geral, podemos afirmar que o agir didático reúne intervenções linguageiras às quais se associam ações não linguageiras e que dizem respeito à ordem da escolha do objeto de ensino (o que e para que), da ordem das estratégias e procedimentos a ser realizados (como?) e adaptados aos alunos (como adaptar?), da ordem das escolhas das ferramentas didáticas (quais?) e da ordem do desenvolvimento do objeto de ensino (que dimensões considerar?). 


\section{PROCEDIMENTOS PARA A INTERPRETAÇÃO DOS GESTOS E DO AGIR DIDÁTICO}

Os gestos didáticos fundamentais foram identificados por meio das análises das interações didáticas entre professores e alunos em contexto de ensino de dois objetos: a subordinada relativa "que" e o texto argumentativo (SCHNEUWLY; DOLZ, 2009).

Três aspectos foram observados: 1) o conteúdo e as categorias gerais desse conteúdo de ensino explorado pelos professores; 2) as instruções das atividades escolares; 3) as formas como os professores desenvolviam seu papel.

Cada gesto foi identificado pela observação de um aspecto desses elementos. 0 gesto de implementação do dispositivo didático centrou-se na análise das instruções orais e escritas (presença de enunciado injuntivo exprimindo a tarefa e de uma ação precisa a ser realizada), nas ferramentas didáticas que constituem o dispositivo e na ação do professor para a realização das atividades escolares referentes à sequência didática voltada para os objetos de ensino. Para a identificação do gesto de regulação, o critério principal foi a observação das intervenções dos professores nos momentos em que os alunos expressavam suas dificuldades quanto à dimensão do objeto de ensino focalizada pela atividade escolar: ferramentas utilizadas, expressões empregadas, etc. 0 gesto de institucionalização foi identificado nos excertos das interações didáticas em que os discursos dos professores se endereçavam ao coletivo da classe e fixavam um conteúdo de forma normativa. O gesto de criação de memória didática foi identificado nas formas de retomadas de conteúdos já estudados em relação ao objeto de ensino específico da situação de ensino. 0 gesto didático de planejamento (SILVA, 2013) foi identificado em dois momentos: 1) na interação verbal do professor em sala de aula com seus alunos em relação ao objeto de ensino: leitura de um gênero textual do eixo do narrar, em que foi possível observar as retomadas realizadas pelos professores quanto ao que foi planejado; e nas entrevistas orais entre professor e pesquisador, quando o professor apresenta o que foi planejado para a aula. São observados no discurso das duas interações os verbos empregados e as ferramentas didáticas citadas e disponibilizadas pelos professores.

Vale ressaltar que na pesquisa desenvolvida os gestos não foram identificados com o objetivo de verificar ou moldar o trabalho do professor, mas como uma ferramenta para a análise dos aspectos enfatizados sobre o objeto de ensino que foram focalizados pelos professores no ato de "ensinar". 
Em relação ao agir didático, as intervenções dos professores em sala de aula foram consideradas como parte desse agir por meio de análises realizadas das ações dos professores (interações verbais em sala de aula entre professores e alunos e os gestos didáticos) e também pela análise das entrevistas de autoconfrontação simples e cruzadas ${ }^{4}$ (CLOT, 2006), em que professores e pesquisadora discutiram as intervenções desses professores no ensino do objeto escolar: leitura e interpretação de dois gêneros do eixo do narrar.

Para as três formas de interações analisadas, seguiram-se os seguintes critérios gerais: 1) identificação do conteúdo temático geral; 2) categorização dos tópicos discursivos que integram o conteúdo temático; 3) identificação dos gestos fundamentais; 4) identificação de outras intervenções. A análise das interações verbais em sala de aula, seguindo os mesmos critérios de análise do grupo Grafe (SCNHEUWLY; DOLZ, 2009), permitiu a identificação, primeiro, dos gestos didáticos. Em seguida, por meio de uma identificação de todos os conteúdos tematizados na interação, percebeu-se a existência de outras intervenções dos professores para além das intervenções didáticas. A análise das interações verbais ocasionadas pelos métodos de autoconfrontação simples e cruzada possibilitou identificar e ampliar características de suas intervenções, ora referentes às intervenções e gestos didáticos, ora referentes a outras intervenções que realizam em sala de aula (questão disciplinar, por exemplo) e fora de sala de aula (reuniões pedagógicas). Essa distinção de intervenções didáticas e não didáticas possibilitou a especificação do agir didático como parte de todo o agir docente. De forma mais específica, na análise das interações verbais que levaram à noção de agir didático foram observados o conteúdo temático em seu aspecto semântico, os actantes no desenvolvimento da atividade (professores, alunos) (MACHADO et al., 2009; MACHADO; BRONCKART, 2009), os tipos de discurso (BRONCKART, 1999), as figuras de ação (BULEA, 2010).

Instrumento metodológico de origem na Psicologia do Trabalho, desenvolvido inicialmente por Faïta (1999), ampliado e modificado por pesquisadores do grupo de pesquisa da Clínica da Atividade do Conservatoire National des Arts et Métiers - Paris (Cnam). 
4. CONSIDERAÇÕES FINAIS: A TRANSPOSIÇÃO DESSES CONCEITOS PARA AS PRÁTICAS DE ENSINO

De modo geral, as constatações sobre os gestos e o agir didático podem contribuir para um entendimento do professor sobre as ações que podem viabilizar ou não o aprendizado dos alunos e suas necessidades específicas sobre um objeto de ensino. Ou seja, o professor pode passar a ter consciência do que, em suas escolhas, é facilitador ou não da aprendizagem, podendo rearticular ou modificar estratégias a fim de alcançar uma formação adequada aos aprendizes. Além de possibilitar a constatação da necessidade de haver tempo e condições favoráveis para que um professor possa realizar adequadamente seu métier.

Discutir sobre os cinco gestos fundamentais e o agir didático, associandoos às situações de ensino de línguas em contexto brasileiro incide sobre a escolha do objeto de ensino e a aprendizagem dos alunos, visando ao desenvolvimento das capacidades (leitoras, de escrita e de conhecimento do funcionamento da língua).

Reconhecemos, portanto, que a problemática maior está no questionamento sobre o que ensinar e que capacidades desenvolver. Nesse caso, o objeto de estudo referente à língua requer tomadas de decisões e escolhas sobre os aspectos a ser considerados para o ensino e isso envolve escolhas teóricas que integram correntes diferentes, conforme já discutimos em nossa primeira seção. Os manuais como Parâmetros Curriculares Nacionais (PCNs), Planos Estaduais, livros didáticos, etc. servem como indicadores a ser usados pelos professores na seleção dos conteúdos.

A escolha do objeto específico requer um aprofundamento por parte do professor em aspectos relacionados ao estudo da língua e às capacidades a ser desenvolvidas nos alunos. Desse modo, a tomada de consciência sobre o gesto de planejamento que leva em consideração a transposição didática do referencial teórico específico e das propostas governamentais adaptando-os ao nível escolar dos alunos contribui para a escolha do objeto a ser ensinado, em função da zona proximal de desenvolvimento (ZPD). O gesto de planejar implica a criação de um dispositivo didático em que há um planejamento sobre as formas de presentificação do objeto e as partes a ser focalizadas a fim de desenvolver diferentes capacidades (de leitura, de escrita, de compreensão da língua, etc.), a ser implantado pelo gesto de implementação desse dispositivo.

Ainda em relação ao objeto de ensino e à aprendizagem dos alunos, 
podemos dizer que pelo gesto de regulação o professor trabalha a superação das dificuldades dos alunos que os impedem de avançar em suas aprendizagens e, consequentemente, desenvolver capacidades de ação com a língua em contextos de leitura, escrita e compreensão de seu funcionamento. Destacamos também a necessidade de o professor, durante 0 desenvolvimento desse gesto, buscar dar autonomia aos alunos para que eles cheguem à superação dos próprios obstáculos. 0 gesto de institucionalização possibilita uma aproximação aos aspectos escolhidos para ser focalizados e que são importantes de ser institucionalizados para o desenvolvimento das capacidades dos alunos quanto aos aspectos referentes à língua. E, por fim, a tomada de consciência sobre o gesto de criação de memória didática possibilita, de um lado, a interação sobre as partes de um mesmo objeto de ensino. De outro lado, a interação entre objetos de ensino estudados anteriormente, ligando-os ao objeto de ensino atual, cria uma relação, a fim de impedir seu esquecimento pelos alunos. Conforme podemos constatar pelo discurso de uma professora participante de uma de nossas pesquisas: “DE: Eu faço isso o tempo todo [...] Os alunos/ eles esquecem sabe/ Então eu tento [...] pelo menos nas minhas aulas [...] mas é difícil fazer isso de um ano para o outro"'.

Conforme discutimos em nossa primeira seção, o trabalho do professor é uma atividade complexa que envolve uma interação com outros (instâncias governamentais, colegas de trabalho, pais, alunos) e, em contexto de ensino propriamente dito, envolve o trabalho sobre um objeto de ensino visando à aprendizagem dos alunos e ao desenvolvimento de capacidades múltiplas. Além disso, é um trabalho auxiliado pelo uso de instrumentos/ ferramentas compreendidos como ferramentas didáticas que possibilitam 0 desenvolvimento do professor, do aluno e da situação de ensino.

No que diz respeito ao trabalho do professor de línguas, a tomada de consciência desses cinco gestos que são fundamentais para o desenvolvimento de seu métier possibilita ao professor a criação de suas próprias ferramentas didáticas adaptadas aos seus contextos de ensino, a fim de suprir as necessidades de seus alunos e as suas próprias. Possibilita também uma melhor compreensão sobre as possíveis improvisações e adaptações a ser realizadas no decorrer da aula, pois reconhecemos que nem tudo planejado é efetivamente realizado.

Uma formação que avalie as intervenções didáticas a respeito desse gesto pode contribuir para um estudo mais aprofundado sobre as possíveis intervenções

Texto de autoconfrontação simples coletado em dezembro de 2011. Parte do corpus coletado por Messias (2013). 
que possam ser mais adequadas para a ampliação real do conhecimento dos alunos.

Relativamente à noção de agir didático, a tomada de consciência de que as ações dos professores em sala de aula são constituídas por intervenções didáticas fundamentais e específicas pode servir aos professores para uma maior compreensão do seu agir em sala de aula, verificando que aspectos desse agir podem ser potencializados em contexto de ensino-aprendizagem. Ao mesmo tempo, tomar consciência do seu agir didático pode contribuir também para uma percepção das teorias que precisam dominar para trabalhar e transformar os objetos de ensino em objeto efetivamente ensinado.

O agir didático possibilita ao professor uma compreensão de que em contexto de ensino existem ações a ser realizadas que dizem respeito, especificamente, ao ensino-aprendizagem, mas que há outras intervenções a ser realizadas por eles em outros contextos de seu trabalho. Essa distinção permite ao professor incidir de forma mais pontual a aspectos relacionados ao ensino e aos possíveis impedimentos para a realização deste trabalho. 


\section{The notions of gesture and didactic action in the education of Portuguese language teachers: interfaces in teaching}

Abstract: In this article, we discuss the notions of fundamental gestures and didactic action concerning primary Portuguese language teachers. Identifying teachers' gestures and didactic action can contribute for a better understanding of teaching. In the present article, we focus on teacher interventions in classroom, specifically concerning how topics are conducted in regard to students' learnings. To discuss these two concepts, we rely on theoretical fields related to the sciences of labor, applied linguistics, and didactics of languages. Methodologically, we discuss the procedures conducted in two studies on three different teaching topics: relative subordinate clause, argumentative essay, and the reading of narrative texts. The identification of teachers' gestures and didactic action about these topics is aimed at specific grammar, discourse, and reading learnings by students. Our results show that the notions of action and didactic gesture can contribute for a better understanding of teaching. They can also be used by teachers to improve ways of acting in classroom.

Keywords: Didactic action. Teaching-learning. Didactic gesture. Teaching. 


\section{REFERÊNCIAS}

AEBY-DAGHÉ, S.; DOLZ, J. Des gestes didactiques fondateurs aux gestes spécifiques à l'enseignemente-apprentissage du texte d'opinion. In: BUCHETON. D.; DEZUTTER, O. (Ėds.). Le développement des gestes professionnels dans l'enseignement du français: un défi pour la recherche et la formation. Bruxelas: De Boeck, 2008. p. 175-196.

AMIGUES, R. Pour une approche ergonomique de l'activité enseignante. Skholê, hors-série, v. 1, p. 5-16, 2003.

BRONCKART, Jean-Paul. Atividade de linguagem, textos e discursos: por um interacionismo sociodiscursivo. Tradução Anna Rachel Machado, Péricles Cunha. 2. ed. São Paulo: Educ, 1999/2007.

. 0 agir nos discursos: das concepções teóricas às concepções dos trabalhadores. Tradução Anna Rachel Machado, Maria de Lourdes Meirelles Matencio. Campinas: Mercado de Letras, 2008.

BUCHETON, D. Professionaliser? Vers une ergonomie du travail des enseignants dans la classe de français. In: BUCHETON. D.; DEZUTTER, O. (Èds.). Le développement des gestes professionnels dans l'enseignement du français: un défi pour la recherche et la formation. Bruxelas: De Boeck, 2008.

; DEZUTTER, O. (Èds.). Le développement des gestes professionnels dans l'enseignement du français: un défi pour la recherche et la formation. Bruxelas: De Boeck, 2008.

BULEA, Ectarina. Linguagem e efeitos desenvolvimentais da interpretação da atividade. Tradução Eulália Vera Lúcia Fraga Leurquin, Lena Lúcia Espínola Rodrigues Figueredo. Campinas : Mercado de Letras, 2010. (Série Ideias sobre Linguagem).

CASTILHO, A. T. de. Nova gramática do português brasileiro. São Paulo: Editora Contexto, 2010. 768 p.

CLOT, Yves. A função psicológica do trabalho. Tradução Adail Sobral. Petrópolis: Vozes, 2006.

DOLZ, J.; GAGNON, R.; DEC NDIO, F. R. Uma disciplina emergente: a didática das línguas. Gêneros textuais: da didática das línguas aos objetos de ensino. São Paulo: Claraluz, 2009. p. 19-50.

FAIITA, D. Analyse des situations de travail: de la parole au dialogue. In: RICHARD-ZAPPELLA, J. (Org.). Espaces de travail, espaces de parole. Rouen: Publications de l'Université de Rouen, 1999. 
MACHADO, Anna Rachel; LOUSADA, Eliane; BARALDI, Glaucimara; ABREUTARDELLI, Lilia Santos; TOGNATO, Maria Izabel Rodrigues. Relações e trabalho educacional: novas perspectivas e métodos no quadro do interacionismo sociodiscursivo. In: ABREU-TARDELLI, L. S.; CRISTÓVÃO, V. L. (Org.). 0 trabalho do professor em uma nova perspectiva. Campinas: Mercado das Letras, 2009.

; BRONCKART, Jean-Paul. (Re-)configurações do trabalho do professor construídas nos e pelos textos: perspectiva metodológica do grupo Alter. In: ABREU-TARDELLI, L. S.; CRISTÓVÃO, V. L. (Org.). 0 trabalho do professor em uma nova perspectiva. Campinas: Mercado das Letras, 2009.

. Ensino de gêneros textuais para o desenvolvimento do professor e de seu trabalho: uma homenagem a Angela Kleiman. In: SERRANI, Silvana. (Org.). Letramento, discurso e trabalho docente. Vinhedo: Horizonte, 2010. p. 161-171.

SILVA, Carla Messias. 0 agir didático do professor de língua portuguesa e sua reconfiguração em textos de autoconfrontação. 2013. 384 f. Tese (Doutorado em Linguística Aplicada e Estudos da Linguagem) - Pontifícia Universidade Católica de São Paulo, São Paulo, 2013.

ORLANDI, E. P. Língua e conhecimento linguístico. São Paulo: Cortez, 2002.

SCHNEUWLY, Bernard. L'objet enseigné. In: SCHNEUWLY, B.; DOLZ, J. (Orgs.). Des objets enseignés en classe de français: le travail de l'enseignant sur la rédaction de textes argumentatifs et sur la subordonnée relative. Genève: Presses Universitaires de Rennes, 2009.

SCHNEUWLY, B. Les outils de l'enseignant. Un essay didactique. Repères: recherches en didactique du français langue maternelle, v. 22, p. 19-38, 2000.

; DOLZ, J. Des objets enseignés en classe de français: le travail de l'enseignant sur la rédaction de textes argumentatifs et sur la subordonnée relative. Genève: Presses Universitaires de Rennes, 2009.

SILVA, A. A. P. D.; SILVA, C. M. R. D. Joaquim Dolz: a pesquisa, uma necessidade para os professores de língua. Revista Nupem, v. 4, n. 7, p. 11-22, 2012.

WIRTHNER, M. La transformation de pratiques d'enseignement par l'outil de travail: observation de séquences d'enseignement du résumé écrit de texte informatif à l'école secondaire. Thèse manuscrite de la Faculté de Psychologie et des Sciences de l'Education de l'Université de Genève, 2006. 
Sobre os autores:

Carla Messias é doutora em Linguística Aplicada e Estudos da Linguagem pela Pontifícia Universidade Católica de São Paulo. Professora de Língua Portuguesa dos níveis fundamental, médio e universitário. Trabalha como pesquisadora na Universidade de Genebra, na unidade de Didática de Línguas.

carlamessias.ribeiro@unige.ch

Joaquim Dolz é doutor em Ciências da Educação. Atua como professor de Didática das Línguas na Universidade de Genebra.

joaquim.dolz-mestre@unige.ch

Recebido em: agosto de 2015

Aprovado em: outubro de 2015 